\title{
A MULTIVARIATE CALIBRATION PROCEDURE FOR THE TENSAMMETRIC DETERMINATION OF DETERGENTS
}

\author{
M. BOS*, P. van MARION and W.E. van der LINDEN \\ Department of Chemical Technology, University of Twente, P.O. Box 217, 7500 AE Enschede \\ (The Netherlands)
}

(Received 22nd June 1988)

\section{SUMMARY}

A multivariate calibration procedure based on singular value decomposition (SVD) and the Ho-Kashyap algorithm is used for the tensammetric determination of the cationic detergents Hyamine 1622, benzalkonium chloride (BACl), $N$-cetyl- $N, N, N$-trimethylammonium bromide $(\mathrm{CTABr})$ and mixtures of $\mathrm{CTABr}$ and $\mathrm{BACl}$. The sensitivity and accuracy depend strongly on the nature of the detergent. Acceptable accuracy is obtained with a two-step calculation procedure in which calibration constants for the total concentration range of interest are used to guide the choice of a more specific set of calibration constants which are valid for a much smaller concentration span. For Hyamine 1622 , concentrations in the range $5 \times 10^{-6}-2 \times 10^{-4} \mathrm{M}$ could be determined with an accuracy of $\pm 10^{-6} \mathrm{M}$. For CTABr, these numbers were $3 \times 10^{-6}-2 \times 10^{-4} \mathrm{M}$ and $\pm 5 \times 10^{-7} \mathrm{M}$; for BACl, they were $2 \times 10^{-3}-9 \times 10^{-2} \mathrm{~g}^{-1}$ and $\pm 1 \times 10^{-3} \mathrm{gl}^{-1}$. In the mixtures of $\mathrm{CTABr}$ and $\mathrm{BACl}$, the accuracies were $\pm 3 \times 10^{-6} \mathrm{M}$ and $\pm 1 \times 10^{-3} \mathrm{gl}^{-1}$, respectively.

Tensammetry (the measurement of non-faradaic admittance) is well established for quantifying detergents [1-7]. Generally, the analytical result is calculated from the depression of the double-layer capacitance or the height of the desorption peak [1]. Britz [6] has pointed out that the choice of the peak height as analytical signal is often not the best, because the reproducibility is poor and because the concentration range over which peak height is linear with concentration is small. Measurement of the depression of the double-layer capacitance suffers from lack of selectivity and moderate sensitivity [1]. Mixtures of surfactants can only be analysed by these techniques if conditions can be found that favor the adsorption of one component without interference of the other components [4].

It has been shown that the multivariate calibration technique based on singular value decomposition and the Ho-Kashyap algorithm (SVDHK) can be applied successfully in cases where interaction between the components of a mixture influences the analytical signal and in cases where this signal is nonlinear with the concentration [8]. The aim of this communication is to show that the SVDHK method is suited to overcome these difficulties in tensammetry. 


\section{THEORY}

The mathematical aspects of the SVDHK method were described earlier [9]. In the calibration or training phase, the method needs an input data matrix $\mathbf{A}$ together with a concentration vector $\mathbf{c}$. The rows of the data matrix are formed by tensammograms that are measured for the calibration samples. The concentrations of the component under study for these samples are stored as the elements in the concentration vector. From these data, the method produces a calibration vector $w$ that can be used to find the concentration of the component by calculating the dot product of $\mathbf{w}$ and the tensammogram measured for an unknown sample:

conc. $=\sum w_{i} i_{i}$

In this equation, the $i_{i}$ values are the a.c. capacitance currents measured at d.c. potentials of the dropping mercury electrode which are also used in the calibration phase; the potentials have fixed intervals spanning the whole adsorption/desorption region.

For the analysis of mixtures, the calibration procedure has to be applied as many times as the number of components that have to be determined. Each time, the same data matrix is used but the concentration vector varies corresponding to the different components. The result is a set of calibration vectors, each specific for one component.

During the calibration phase, a decision has to be made regarding the number of singular values that will be taken into account. Several procedures can be followed to direct this choice. The procedure based on singular value decomposition shows the singular values in descending order to the operator. If there is a clear break between two successive values in this sequence, the number can be chosen in such a way that only the significant singular values are included, the small ones being omitted. If there is no clear break, the optimal number of singular values for the problem has to be found by trial and error. The best choice then is the minimum number of singular values that produces an acceptable value of the root-mean-square (RMS) error in the leave-oneout method. In this method, each member of the calibration set is successively left out of the calibration and used to calculate a prediction of its concentration based on a calibration with the remaining members. The RMS error is calculated from the individual differences between the known concentrations of the samples and their predicted values.

\section{EXPERIMENTAL}

\section{Chemicals}

Sodium sulfate (Merck, zur Analyse), diisobutylphenoxyethoxyethyldimethylbenzylammonium chloride monohydrate (Hyamine, 1622; Fluka), benzalkonium chloride (BACl; Fluka, purum) and $N$-cetyl- $N, N, N$-trimethylammonium bromide (CTABr; Merck, zur Analyse) were used as received. All 
solutions were prepared with deionized water that was filtered through Millipore Q2 filters. Nitrogen (Hoekloos, quality "very pure") was used to remove oxygen by bubbling it through the samples for $20 \mathrm{~min}$.

\section{Equipment}

Tensammograms were recorded with a traditional setup for phase-selective a.c. polarography consisting of a three-electrode polarographic system (PAR model 174), an interface for a.c. polarography (PAR model 174/50) and a lock-in amplifier (PAR model 122). The drop life of the dropping mercury electrode (DME) was controlled electromechanically by a Radiometer timer (type DLT1). The instrumentation was operated under computer control (PDP-11/84 and laboratory peripheral system LPS-11 with 12bit ADC and DACs from Digital Equipment Corp.). Graphic display on a chart recorder (Philips PM8100) of the computer-recorded tensammograms provided a convenient check on the correct operation of the complete system.

Three electrodes were used in the polarographic cell: the DME, a calomel reference electrode (SCE; Metrohm 06.0702.100) and a mercury pool at the bottom of the cell as the auxiliary electrode. The DME characteristics were $h=50 \mathrm{~cm}$, natural drop time $4.05 \mathrm{~s}$ in $0.1 \mathrm{M}$ sodium sulfate with open circuit and $m=2.19 \mathrm{mg} \mathrm{s}^{-1}$.

\section{Computer programs}

The data-acquisition software was mainly written in FORTRAN-77 while the timing and $\mathrm{AD}$-conversion routines were written in MACRO-11. The program runs under the RSX-11M operating system (Digital Equipment Corp) and synchronizes the measurements with the drop time of the DME. The SVDHK program was essentially the same as that used before $[7,8]$ but was rewritten in F77 to run under RSX-1M and extended with utilities to smooth and store or retrieve tensammograms together with filing information.

\section{Procedures}

For all samples $0.1 \mathrm{M}$ sodium sulfate was used as the supporting electrolyte. The frequency of the a.c. modulation was $80 \mathrm{~Hz}$, its amplitude $10 \mathrm{mV}$. The a.c. response was measured at a phase difference of $135^{\circ}$ with the applied a.c. modulation at d.c. potentials versus SCE ranging from $-0.1 \mathrm{~V}$ to $-1.6 \mathrm{~V}$. The d.c. scan rate was $2 \mathrm{mV} \mathrm{s}^{-1}$. The mechanical drop time was set at $1 \mathrm{~s}$. During the d.c. scans, the computer records 751 a.c. current/d.c. ramp potential pairs, one pair for every drop dispensed by the DME. The raw data are treated by a spikepicking routine that removes the occasional spikes caused by premature drop fall or a failing drop knock. The resulting tensammogram is then subjected to a Savitzky-Golay smoothing routine (25-point quadratic). From this smoothed tensammogram, a similar tensammogram recorded for the blank solution of the supporting electrolyte is subtracted. Then 29 points equidistant on the d.c. 


\section{TABLE 1}

Calibration results for Hyamine 1622, CTABr and $\mathrm{BACl}$

\begin{tabular}{|c|c|c|c|}
\hline \multirow{2}{*}{$\frac{\text { Compound }}{\text { Conc. range }^{a}}$} & \multicolumn{3}{|l|}{ Hyamine 1622} \\
\hline & $5 \times 10^{-6}-2 \times 10^{-4}$ & $5 \times 10^{-6}-10^{-4}$ & $7 \times 10^{-5}-2 \times 10^{-4}$ \\
\hline No. of diff. concs. & 18 & 13 & 9 \\
\hline $\begin{array}{l}\text { Total no. of } \\
\text { samples }\end{array}$ & 54 & 42 & 22 \\
\hline $\begin{array}{l}\text { No. of data } \\
\text { points per } \\
\text { sample }\end{array}$ & 29 & 29 & 29 \\
\hline $\begin{array}{l}\text { No. of } \\
\text { sing. values }\end{array}$ & 10 & 8 & 10 \\
\hline $\begin{array}{l}\text { RMS error } \\
\text { recognition }\end{array}$ & $1.2 \times 10^{-6}$ & $4.2 \times 10^{-7}$ & $9.5 \times 10^{-7}$ \\
\hline $\begin{array}{l}\text { RMS error } \\
\text { prediction }^{\mathrm{a}}\end{array}$ & $5.3 \times 10^{-6}$ & $1.0 \times 10^{-6}$ & $1.3 \times 10^{-5}$ \\
\hline
\end{tabular}

\begin{tabular}{|c|c|c|c|}
\hline \multirow{2}{*}{$\frac{\text { Compound }}{\text { Conc. range }^{\mathbf{a}}}$} & \multicolumn{3}{|c|}{ Cetyltrimethylammoniumbromide } \\
\hline & $3 \times 10^{-6}-4 \times 10^{-5}$ & $4 \times 10^{-5}-8 \times 10^{-5}$ & $8 \times 10^{-5}-2 \times 10^{-4}$ \\
\hline No. of diff. concs. & 13 & 6 & 7 \\
\hline $\begin{array}{l}\text { Total no. of } \\
\text { samples }\end{array}$ & 29 & 14 & 16 \\
\hline $\begin{array}{l}\text { No. of data } \\
\text { points per } \\
\text { sample }\end{array}$ & 29 & 15 & 15 \\
\hline $\begin{array}{l}\text { No. of } \\
\text { sing. values }\end{array}$ & 4 & 6 & 5 \\
\hline $\begin{array}{l}\text { RMS error } \\
\text { recognition }^{\mathrm{a}}\end{array}$ & $4.5 \times 10^{-7}$ & $6.0 \times 10^{-7}$ & $2.0 \times 10^{-6}$ \\
\hline $\begin{array}{l}\text { RMS error } \\
\text { prediction }^{a}\end{array}$ & $7.0 \times 10^{-7}$ & $4.0 \times 10^{-6}$ & $2.0 \times 10^{-5}$ \\
\hline Compound & \multicolumn{3}{|c|}{ Benzalkonium chloride } \\
\hline Conc. range ${ }^{a}$ & $2 \times 10^{-3}-9 \times 10^{-2}$ & $2 \times 10^{-3}-2.6 \times 10^{-2}$ & $4 \times 10^{-2}-9 \times 10^{-2}$ \\
\hline No. of diff. concs. & 26 & 14 & 12 \\
\hline $\begin{array}{l}\text { Total no. of } \\
\text { samples }\end{array}$ & 62 & 36 & 23 \\
\hline $\begin{array}{l}\text { No. of data } \\
\text { points per } \\
\text { sample }\end{array}$ & 29 & 15 & 15 \\
\hline $\begin{array}{l}\text { No. of } \\
\text { sing. values }\end{array}$ & 12 & 8 & 8 \\
\hline $\begin{array}{l}\text { RMS error } \\
\text { recognition }^{a}\end{array}$ & $1.0 \times 10^{-3}$ & $2.8 \times 10^{-4}$ & $5.8 \times 10^{-4}$ \\
\hline $\begin{array}{l}\text { RMS error } \\
\text { prediction }^{a}\end{array}$ & $4.2 \times 10^{-3}$ & $3.3 \times 10^{-3}$ & $4.0 \times 10^{-3}$ \\
\hline
\end{tabular}

${ }^{a}$ Concentrations and RMS errors are given in molarity for Hyamine 1622 and CTABr, and in $\mathrm{g}$ $\mathbf{1}^{-1}$ for $\mathrm{BACl}$. 
scan axis are chosen at $50-\mathrm{mV}$ intervals and used as a row for the data matrix or, in the case of an unknown sample, as the pattern vector for the dot product calculation to find the concentration.

Calibration for the single-component systems was done with a set of 50-60 tensammograms per surfactant. This set contains duplicate or triplicate measurements for the concentrations used. Generally, 15-20 different concentrations of the surfactant were used in this calibration set. For the determinations of mixtures of $\mathrm{BACl}$ and $\mathrm{CTABr}$, the calibration set comprised 36 measurements on $\mathrm{BACl}$ alone, 30 measurements on $\mathrm{CTABr}$ alone, and 50 measurements on mixtures of CTABr and BACl.

The decision on the number of singular values to be considered was based on observation of the RMS error; the number used was one less than the number for which the RMS error did not improve significantly.

\section{RESULTS AND DISCUSSION}

Table 1 shows the results for Hyamine 1622, CTABr and $\mathrm{BACl}$ examined separately in $0.1 \mathrm{M}$ sodium sulfate. Figure 1 shows a typical tensammogram

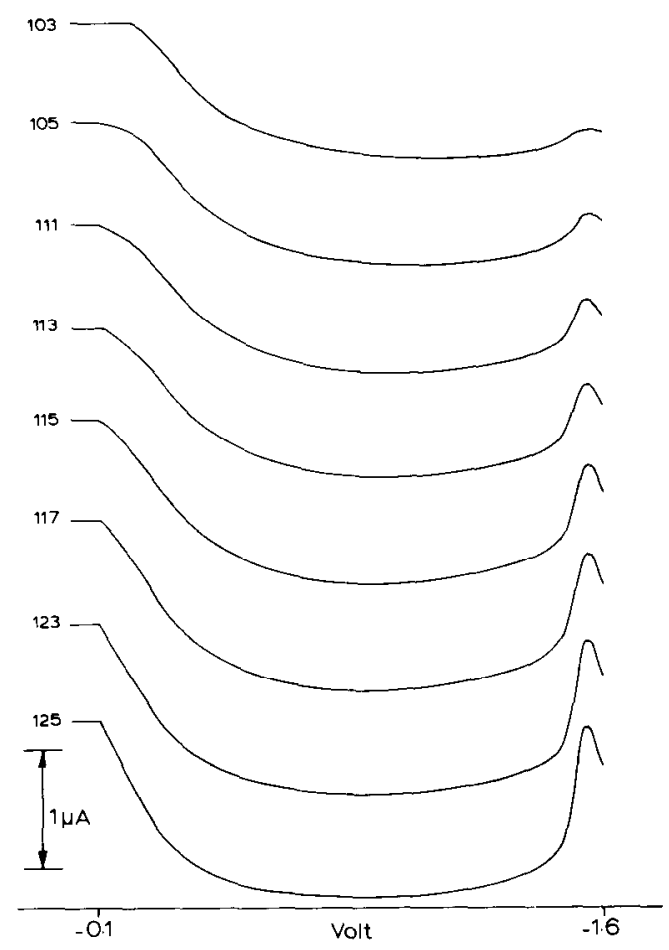

Fig. 1. Tensammograms of 0.110 (upper curve), $0.218,0.323,0.426,0.527$ and $0.626 \times 10^{-4} \mathrm{M}$ Hyamine 1622 in $0.1 \mathrm{M}$ sodium sulfate. 


\section{TABLE 2}

Calibration results for $\mathrm{CTABr} / \mathrm{BACl}$ mixtures

\begin{tabular}{lll}
\hline Detergent & CTABr & BACl \\
Conc. range & $3 \times 10^{-6}-9 \times 10^{-5} \mathrm{M}$ & $2 \times 10^{-3}-4 \times 10^{-2} \mathrm{~g} \mathrm{l}^{-1}$ \\
No. of different concs. & 31 & 33 \\
Total no. of samples & 116 & 116 \\
No. of data points per sample & 29 & 29 \\
No. of singular values & 9 & 12 \\
RMS error recognition & $2.7 \times 10^{-6} \mathrm{M}$ & $9.2 \times 10^{-4} \mathrm{~g} \mathrm{l}^{-1}$ \\
RMS error prediction & $7.3 \times 10^{-6} \mathrm{M}$ & $1.6 \times 10^{-3} \mathrm{~g} \mathrm{l}^{-1}$ \\
\hline
\end{tabular}

for Hyamine 1622. A comparison of the RMS errors for recognition and for prediction shows that the performance of the calibration vector $w$ is better in the calculation of a concentration of a sample that was present in the calibration set than it is for a sample that was left out of it and which can be considered as an unknown sample.

The results in Table 1 also show that it is advantageous to use multiple calibration vectors, each for a part of the total concentration range. The calibration vector spanning the total range can be used for the choice of the more specific vector. For benzalkonium chloride, the calibration results for the separate concentration ranges were better when the number of data points used was diminished to 15 to keep the data set overdetermined. The performance of the method for CTABr is less satisfactory than for the other components. The concentration range had to be split into three parts to obtain reasonable recognition results, but the prediction results for the highest concentration range remained poor.

The method can also be used for the analysis of mixtures of detergents as is demonstrated by the results given in Table 2 . In this case, two calibration vectors were calculated from the same data set, one for each component of the mixture. The results are less accurate than for the single-component systems, especially for the prediction of the (zero) concentration of an absent component.

The calibration procedure for a training set of 60 samples is quite an investment in human labor to prepare and run the samples. Therefore the method is useful only if the calibration results can be used over a long time. This requires equipment of good stability and proper handling of the reference electrode. The results in Table 3, where the calibration vector for Hyamine 1622 is applied to measurements done on different days, show that these requirements can be met. 


\section{TABLE 3}

Long-term stability test for tensammetry of Hyamine 1622 in $0.1 \mathrm{M}$ sodium sulfate

\begin{tabular}{|c|c|c|c|c|c|c|c|}
\hline \multirow[t]{2}{*}{ Day } & \multicolumn{2}{|c|}{ Conc. $\left(10^{-4} \mathrm{M}\right)$} & \multirow{2}{*}{$\begin{array}{l}\text { Error } \\
(\%)\end{array}$} & \multirow[t]{2}{*}{ Day } & \multicolumn{2}{|c|}{ Conc. $\left(10^{-4} \mathrm{M}\right)$} & \multirow{2}{*}{$\begin{array}{l}\text { Error } \\
(\%)\end{array}$} \\
\hline & Given & Found & & & Given & Found & \\
\hline \multirow[t]{11}{*}{1} & 0.110 & 0.105 & 4.5 & 70 & 0.055 & 0.055 & 0.0 \\
\hline & 0.110 & 0.099 & 10.0 & & 0.055 & 0.052 & 5.5 \\
\hline & 0.218 & 0.228 & 4.6 & & 0.110 & 0.110 & 0.0 \\
\hline & 0.218 & 0.221 & 1.4 & & 0.110 & 0.116 & 5.6 \\
\hline & 0.323 & 0.325 & 0.6 & & 0.164 & 0.164 & 0.0 \\
\hline & 0.323 & 0.327 & 1.2 & & 0.164 & 0.157 & 4.3 \\
\hline & 0.426 & 0.427 & 0.2 & & & & \\
\hline & 0.426 & 0.430 & 0.9 & 71 & 0.323 & 0.325 & 0.6 \\
\hline & & & & & 0.323 & 0.328 & 1.5 \\
\hline & & & & & 0.426 & 0.428 & 0.5 \\
\hline & & & & & 0.426 & 0.429 & 0.7 \\
\hline
\end{tabular}

\section{REFERENCES}

1 E. Bednarkiewicz and Z. Kublik, Anal. Chim. Acta, 176 (1985) 133.

2 H. Batycka and Z. Lukaszewski, Anal. Chim. Acta., 162 (1984) 207, 215.

3 D.R. Canterford, J. Electroanal. Chem., 118 (1981) 395; Anal. Chim. Acta, 94 (1977) 377.

4 D.R. Canterford, J. Electroanal. Chem., 111 (1980) 269.

5 D.R. Canterford and R.J. Taylor, J. Electroanal. Chem., 98 (1979) 25.

6 D. Britz, Anal. Chim. Acta, 115 (1980) 327.

7 M. Bos, Anal. Chim. Acta, 135 (1982) 249.

8 M. Bos, Anal. Chim. Acta, 166 (1984) 261.

9 M. Bos and G. Jasink, Anal. Chim. Acta, 103 (1978) 151. 